\title{
Diclofenac Mouthwash as a potential therapy for reducing pain and discomfort in chemo-radiotherapy-induced oral mucositis
}

Peter A Brennan (1)

Rowena Lewthwaite (1)

Poornima Sakthithasan (1)

Sharon McGuigan (1)

Oliver Donnelly (2)

Peyman Alam (1)

Ricardo S Gomez (3)

Stefano Fedele $(4,5)$

Department of Oral and Maxillofacial Surgery (1) and Clinical Oncology (2) Queen Alexandra Hospital, Portsmouth, PO6 3LY, UK

Department of Oral Surgery and Pathology, School of Dentistry, Universidade Federal de Minas Gerais, Belo Horizonte, Brazil

University College London, Eastman Dental Institute (4)

256 Grays Inn Rd, London WC1X 8LD, UK

NIHR University College London Hospital Biomedical Research Centre, Maple House 1st floor, 149 Tottenham Court Road, London W1T 7DN (5)

Correspondence to PA Brennan

Tel +44 2392286736

Fax +44 2392286089

Email: peter.brennan@porthosp.nhs.uk 


\section{Abstract}

Aims: Oral and/or oropharyngeal acute mucositis during and after chemoradiotherapy (chemo-RT) for head and neck squamous cell carcinoma (HNSCC) can be extremely painful, sometimes requiring nasogastric feeding to enable adequate nutrition. The MASCC/ISOO evidence- based guidelines recommend benzydamine mouthwash for mucositis prevention in RT (recently updated to include chemo-RT), and a Cochrane systematic review found other agents to be effective in prophylaxis. Diclofenac mouthwash is licenced for painful oral mucosal inflammatory conditions but to our knowledge has not been assessed in chemo-RT associated oral mucositis.

Method: A clinical observation and service evaluation study in 10 patients undergoing chemo-RT for HNSCC to assess the potential value of diclofenac mouthwash $(0.74 \mathrm{mg} / \mathrm{ml})$ in reducing symptoms. Patients used $20 \mathrm{ml}$ of mouthwash up to 4 times a day starting in week 3 (of a 6 week course of treatment), recording pain and discomfort scores using a visual analogue scale on days $0,1,7$ and 14 (until the end of week 4). As per our current clinical practice, oral mucositis was not clinically scored as an outcome. Statistical analysis was performed using a one-way ANOVA.

Results: Using diclofenac mouthwash, 9/10 patients experienced pain score reduction from day 0 (mean score $6.75+/$ - SD 1.83) to day $2(5.05+/-$ SD 1.62) and day 14 (4.09+/- SD 1.96).

Conclusions: Diclofenac mouthwash may be beneficial for managing chemo$\mathrm{RT}$-induced oral mucositis. While a prospective randomised clinical trial is needed, it can be prescribed for this condition within its current licence. 
Key words: oral mucositis, radiotherapy, diclofenac, mouthwash, pilot study.

\section{Introduction}

Oral mucositis is a common side effect that occurs during treatment for head and neck squamous cell carcinoma (HNSCC) with external beam radiotherapy (RT), and chemo-radiotherapy therapy (chemo-RT). Oral mucositis can progress to ulceration and sub-mucosal changes (1) and have a significant negative impact on the patient's quality of life and result in dysphagia, dehydration and poor nutrition (2).

Though many drugs are available, there is currently no approved therapy for oral mucositis (1). Various agents have been advocated for both prevention and symptom control. In their evidence-based clinical practice guidelines for mucositis secondary to cancer therapy (3), the Multinational Association for Supportive Cancer Care (MASCC) and International Society of Oral Oncology (ISOO) recommend that $0.2 \%$ morphine mouthwash and $0.5 \%$ doxepin mouthwash may be effective to treat pain due to oral mucositis in patients treated by chemo-RT.

Benzydamine (Difflam) mouthwash, a non-steroidal anti-inflammatory drug that acts by inhibiting pro- inflammatory cytokines including TNF- $\alpha$ is also recommended by MASCC and to prevent oral mucositis in patients with head 
and neck cancer receiving moderate dose RT (up to $50 \mathrm{~Gy}$ ). Recently this has been updated to include patients undergoing chemo-RT (4).

A Cochrane systematic review of interventions for preventing oral mucositis included 89 useable studies and evaluated various agents. Those with some benefit (with variable strength of evidence for use during chemotherapy, chemo-RT and RT regimes) included ice chips, amifostine benzydamine and Chinese medicine, honey and zinc sulphate (5).

A systematic review of the many natural products such as vitamins, plant extracts, chamomile, aloe vera, glutamine and manuka honey that have been used for both prophylaxis and symptom control in oral mucositis has recently been published by MASCC/ISOO and use of oral glutamine was suggested. (6)

Other methods including photo-bio-modulation (PBM) such as low-level laser therapy are also used by some for both prevention and/or treatment of oral mucositis. A recent MASCC/ISOO systematic review is available (7). Finally, several novel biological agents including recombinant human interleukin-11 and recombinant human keratinocyte growth factor-1 are currently undergoing phase II/III clinical trials and the results are awaited with interest. A recent comprehensive summary of these potential agents is available (1).

Diclofenac, a powerful non-steroidal anti-inflammatory drug, has been used topically for musculoskeletal disorders and pain (8). Its mechanism of action is 
via cyclo-oxygenase-2 (COX-2) inhibition, reducing angiogenesis and induction of apoptosis. More recently, diclofenac mouthwash $(0.74 \mathrm{mg} / \mathrm{ml})$ has been assessed for painful oral mucosal conditions and following periodontal surgery $(9,10)$. It is currently licenced in the UK (and in other countries) for symptom control of painful inflammatory conditions of the oral mucosa (Figure 1). We regularly prescribe this mouthwash to help control oral symptoms in patients with HNSCC undergoing chemo- RT but to date only have anecdotal evidence of its potential benefit.

\section{Methods}

No ethical committee approval was required for this clinical observation/service evaluation study in a small group of 10 head and neck cancer patients as our practice was not changed. Ten patients who were undergoing intensity modulated RT (IMRT) treatment (65Gy in 30 fractions) for tongue base $(n=6)$ or tonsillar SCC $(n=4)$ were included. Eight of the primary tumours were staged as T2 while two were T4a. Eight patients had positive neck nodes at the time of diagnosis. Seven patients had concurrent chemotherapy during RT while 3 patients had RT only. Patients were only included if they were not already using opioid analgesia during the period of evaluation. Patients were prescribed the mouthwash from the beginning of week 3 (of a 6 week course of treatment), and were instructed to use $20 \mathrm{ml}$ and to gargle for 1-2 minutes up to 4 times per day, before spitting it out. Patients were asked to score their discomfort during 14 days of using the mouthwash on a sheet containing a visual analogue scale (VAS) with 0 for no 
pain to 10 for unbearable pain at day 0 (before using the mouthwash for the first time), day 1, day 2, day 7 and day 14 (until the end of week 4 of therapy). All scores were put on an Excel spread sheet. The mean and SD were calculated and the results were analysed using a single way ANOVA. No formal scoring system was used to assess oral mucositis severity during treatment as this is not the routine practice of the oncologists in our unit.

\section{Results}

Seven men and three women completed VAS while using diclofenac mouthwash during their cancer treatment. The mean age was 71 years (range 54 - 87 years). Initial assessment of the VAS sheets found that $9 / 10$ patients experience some improvement in their oral mucositis symptoms using diclofenac mouthwash over the 2-week period of observation (Figure 2). A statistically significant difference was found between the mean VAS scores over the 2 week period (ANOVA F-stat 5.83, $\mathrm{P}=0.0083$ ) (Table 1).

\section{Discussion}

Oral mucositis can be an extremely debilitating complication of chemo-RT treatment for HNSCC. Many drugs and other agents have been tried for both the prevention and treatment of oral mucositis with varying success. Currently recommendations including the use of benzydamine have been published by MASCC/ISOO $(3,4,6,7)$. Our preliminary observations suggest that diclofenac mouthwash might have some benefit in the symptom control of this painful 
condition. In some respects, this is not surprising given its anti-inflammatory properties which also account for the therapeutic benefits of both aspirin and benzydamine in painful sore throats (8). However, the longer term use of antiinflammatory agents can be associated with oral mucosa irritation, sensitization and paradoxical worsening pain.

In addition to the small size of our pilot study (10 patients), a potential confounding factor is the progressive development and worsening of oral mucositis in many patients as the cancer treatment continues over several weeks. A prospective randomised clinical trial is being considered, but the study design will need careful planning to take in to account the likelihood of worsening mucositis during RT or chemo-RT treatments, and the need for opioids to control pain in some patients.

However, given that diclofenac mouthwash is available and is licenced for use in painful inflammatory oral mucosal conditions, and to date has not received attention by MASCC/ISOO or others, we wanted to use this paper to raise awareness of its potential use and benefit in RT-induced oral mucositis.

Acknowledgements: The diclofenac mouthwash used in this study was manufactured by Morningside Healthcare, Leicester, UK. We are grateful to Martyn Roberts, Medical Photographer, Queen Alexandra Hospital, Portsmouth, UK for Figure 1. 
Financial support: Product was supplied gratis, but no financial support was given for the conduct or evaluation of this service evaluation study.

Conflict of interest: none. 


\section{$\underline{\text { References }}$}

1. Blakaj A, Bonomi M, Gamez ME, Blakaj DM. Oral mucositis in head and neck cancer: Evidence-based management and review of clinical trial data. Oral Oncol. 2019;95:29-34.

2. Lalla RV, Brennan MT, Gordon SM, Sonis ST, Rosenthal DI, Keefe DM. Oral Mucositis Due to High-Dose Chemotherapy and/or Head and Neck Radiation Therapy. J Natl Cancer Inst Monogr. 2019;(53). doi: 10.1093/jncimonographs/lgz011.

3. MASCC/ISOO 2014 guidelines available at: https://www.mascc.org/assets/GuidelinesTools/mascc\%20isoo\%20mucositis\%20guidelines $\% 20$ summary\%207n ov2014.pdf

4. Ariyawardana A, Cheng KK, Kandwal A, Tilly V, Al-Azri AR, Galiti D, et al. Mucositis Study Group of the Multinational Association of Supportive Care in Cancer/International Society for Oral Oncology (MASCC/ISOO). Systematic review of anti-inflammatory agents for the management of oral mucositis in cancer patients and clinical practice guidelines. Support Care Cancer. 2019;27:3985-3995.

5. Worthington HV, Clarkson JE, Eden OB. Interventions for preventing oralmucositis for patients with cancer receiving treatment. Cochrane Database Syst Rev. 2007;4:CD000978.

6. Yarom N, Hovan A, Bossi P, Ariyawardana A, Jensen SB, Gobbo M, et al. Mucositis Study Group of the Multinational Association of Supportive Care in Cancer / International Society of Oral Oncology 
(MASCC/ISOO). Systematic review of natural and miscellaneous agents for the management of oral mucositis in cancer patients and clinical practice guidelines-part 1: vitamins, minerals, and nutritional supplements. Support Care Cancer. 2019;27:3997-4010.

7. Zadik Y, Arany PR, Fregnani ER, Bossi P, Antunes HS, Bensadoun RJ, et al. Mucositis Study Group of the Multinational Association of Supportive Care in Cancer/International Society of Oral Oncology (MASCC/ISOO). Systematic review of photo-bio-modulation for the management of oral mucositis in cancer patients and clinical practice guidelines. Support Care Cancer. 2019;27:3969-3983.

8. Honvo G, Leclercq V, Geerinck A, Thomas T, Veronese N, Charles A, et al. Safety of Topical Non-steroidal Anti-Inflammatory Drugs in Osteoarthritis: Outcomes of a Systematic Review and Meta-Analysis. Drugs Aging. 2019;36(Suppl 1):45-64 .

9. Serafini G, Trevisan S, Saponati G, Bandettini B. Therapeutic Efficacy and Tolerability of the Topical Treatment of Inflammatory Conditions of the Oral Cavity with a Mouthwash Containing Diclofenac Epolamine : A Randomized, Investigator-Blind, Parallel-Group, Controlled, Phase III Study. Clin Drug Investig. 2012;32:41-49.

10. Agarwal A, Nath SS, Goswami D, Gupta D, Dhiraaj S, Singh PK. An evaluation of the efficacy of aspirin and benzydamine hydrochloride gargle for attenuating postoperative sore throat: a prospective, randomized, single-blind study. Anesth Analg. 2006;103:1001-3. 
Table 1 Summary of results showing mean, standard deviation (SD) and ANOVA for the 10 patients who participated in this study.

\begin{tabular}{|c|c|c|c|c|c|}
\hline \multicolumn{6}{|c|}{ Data Summary } \\
\hline $\begin{array}{l}\text { Days from } \\
\text { start of } \\
\text { mouthwash }\end{array}$ & $\mathbf{N}$ & Mea & \multicolumn{2}{|c|}{ Std.Dev. } & Std.Error \\
\hline Day 0 & 10 & 6.75 & \multicolumn{2}{|c|}{1.83} & 0.58 \\
\hline Day 2 & 10 & 5.0 & \multicolumn{2}{|c|}{1.62} & 0.51 \\
\hline Day 14 & 10 & 4.0 & \multicolumn{2}{|c|}{1.96} & 0.59 \\
\hline \multicolumn{5}{|c|}{ ANOVA Summary } & \\
\hline Source & $\begin{array}{c}\text { Degrees of } \\
\text { Freedom } \\
\text { DF }\end{array}$ & $\begin{array}{c}\text { Sum of } \\
\text { Square } \\
\text { SS }\end{array}$ & $\begin{array}{c}\text { Mean } \\
\text { Square } \\
\text { MS }\end{array}$ & F-Stat & P-Value \\
\hline $\begin{array}{c}\text { Between } \\
\text { Groups }\end{array}$ & 2 & 37.68 & 18.84 & 5.72 & 0.0083 \\
\hline $\begin{array}{l}\text { Within } \\
\text { Groups }\end{array}$ & 28 & 92.26 & 3.30 & & \\
\hline Total: & 30 & 129.93 & & & \\
\hline
\end{tabular}


Figure 1. Commercially available diclofenac mouthwash.

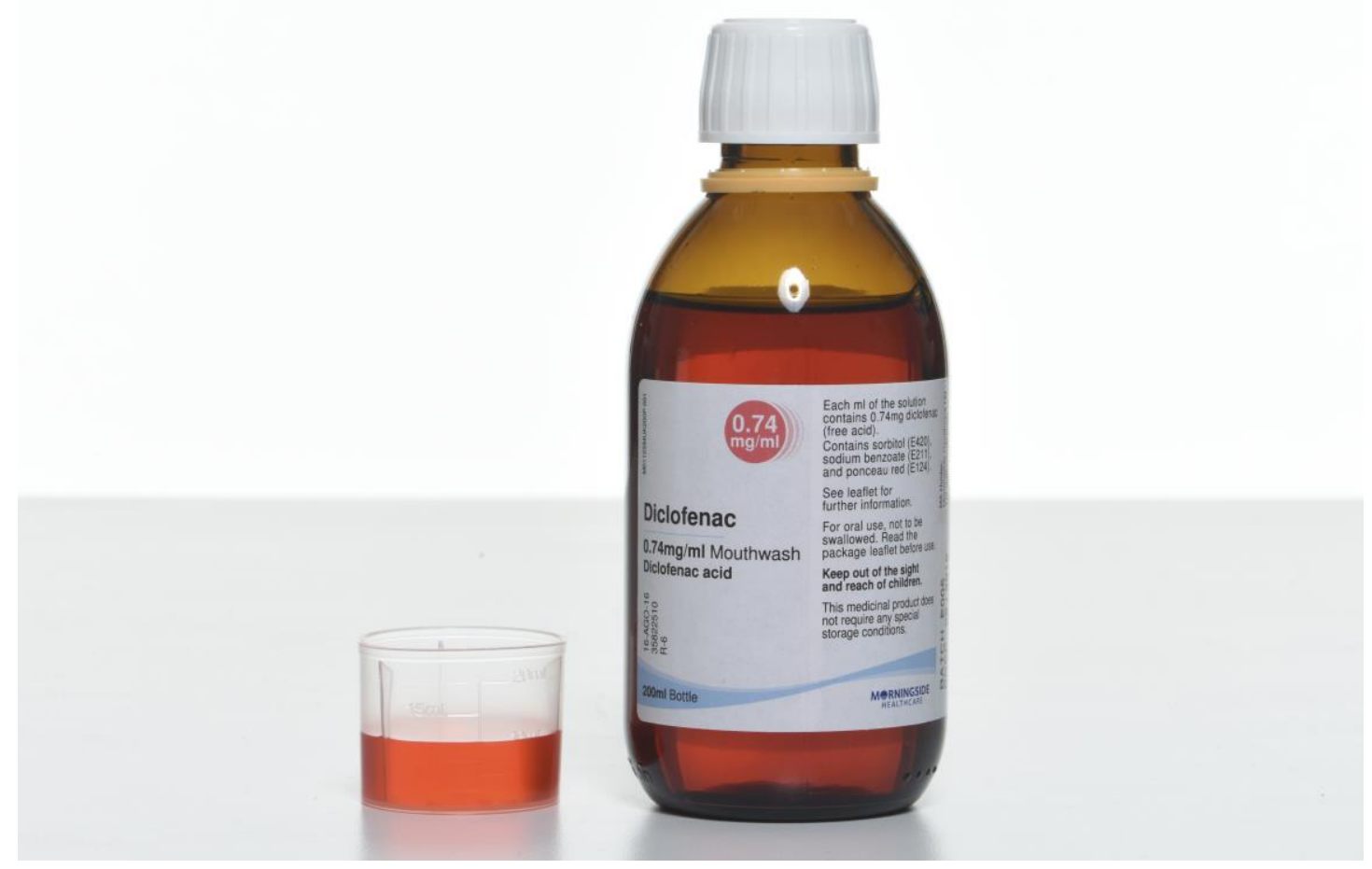


Figure 2. Visual analogue scores of the 10 patients at Day 0, 2 and 14 .

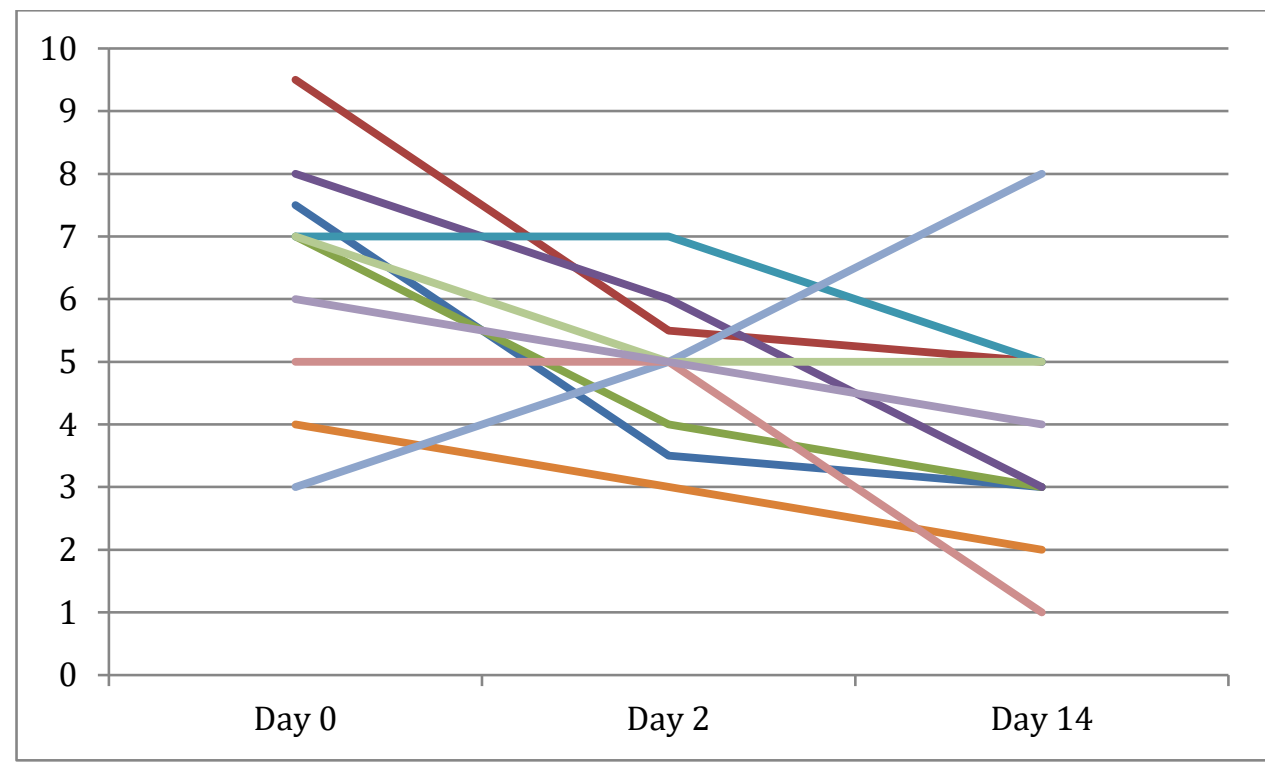

